\title{
MRI following scoliosis surgery? An analysis of implant heating, displacement, torque, and susceptibility artifacts
}

\author{
Andreas Heinrich $^{1}$ (D) - Maximilian Reinhold ${ }^{1}$ • Felix V. Güttler ${ }^{1}$ • Georg Matziolis ${ }^{2}$ • Ulf K.-M. Teichgräber ${ }^{1}$ • \\ Timo Zippelius ${ }^{2} \cdot$ Patrick Strube $^{2}$
}

Received: 14 July 2020 / Revised: 21 October 2020 / Accepted: 19 November 2020 / Published online: 4 December 2020

(C) The Author(s) 2020

\begin{abstract}
Objectives The implant constructs used in scoliosis surgery are often long with a high screw density. Therefore, it is generally believed that magnetic resonance imaging (MRI) should not be carried out after scoliosis surgery, with the result that computed tomography is often preferred despite the ionizing radiation involved. The objective of this study was to evaluate the MRI compatibility of long pedicle-screw-rod constructs at $1.5 \mathrm{~T}$ and $3 \mathrm{~T}$ using standardized methods of the American Society for Testing and Materials (ASTM).

Methods Constructs between 130 and $430 \mathrm{~mm}$ long were systematically examined according to the ASTM standards F2182 (radio frequency-induced heating), F2119 (susceptibility artifacts), F2213 (magnetically induced torque), and F2052 (magnetically induced displacement force).

Results The maximum heating in the magnetic field was $1.3 \mathrm{~K}$. Heating was significantly influenced by magnetic field strength $(p<0.001)$, implant length $(p=0.048)$, and presence of cross-links $(p=0.001)$. The maximum artifact width for different lengths of the anatomically bent titanium rods with CoCr alloy ranged between $14.77 \pm 2.93 \mathrm{~mm}$ (TSE) and 17.49 $\pm 1.82 \mathrm{~mm}$ (GRE) for $1.5 \mathrm{~T}$ and between $23.67 \pm 2.39 \mathrm{~mm}$ (TSE) and $27.77 \pm 2.37 \mathrm{~mm}$ (GRE) for $3 \mathrm{~T}$. TiCP and TiAl showed the smallest and $\mathrm{CoCr}$ and $\mathrm{CoCr}$ Plus the largest artifact widths. The magnetically induced torque and displacement force were negligible.

Conclusions MRI following scoliosis surgery with long implant constructs is safe with the patient in supine position. Although susceptibility artifacts can severely limit the diagnostic value, the examination of other regions is possible.

Key Points

- Large spinal implants are not necessarily a contraindication for MRI; MR conditional status can be examined according to the ASTM standards F2182, F2119, F2213, and F2052.

- A metallic pedicle-screw-rod system could be reliably and safely examined in all combinations of length (130 to $430 \mathrm{~mm}$ ), configuration, and material in $a B_{0}$ at $1.5 T$ and $3 T$.

- According to ASTM F2503, the examined pedicle-screw-rod system is MR conditional and especially the young patients can benefit from a non-ionizing radiation MRI examination.
\end{abstract}

Keywords Cobalt $\cdot$ Magnetic resonance imaging $\cdot$ Safety $\cdot$ Spine $\cdot$ Titanium

Timo Zippelius and Patrick Strube contributed equally to this work.

Andreas Heinrich

andreas.heinrich@med.uni-jena.de

1 Department of Radiology, Jena University Hospital - Friedrich Schiller University, Am Klinikum 1, 07747 Jena, Germany

2 Department of Orthopedics, Jena University Hospital, Campus Eisenberg, Klosterlausnitzer Straße 81, 07607 Eisenberg, Germany

\begin{tabular}{ll}
\multicolumn{2}{l}{ Abbreviations } \\
ASTM & American Society for Testing and Materials \\
CoCr Plus & Cobalt-chromium-molybdenum \\
CoCr & Cobalt-chromium \\
RF & Radio frequencies \\
Ti & Titanium \\
TiAl & Titanium aluminide \\
TiCP & Pure titanium alloy
\end{tabular}




\section{Introduction}

The use of metallic implants such as pedicle screws and rods is currently standard in spinal surgery to treat deformity, degeneration, destruction, and trauma [1,2]. Especially in patients with deformity, the implants may be long and the constructs may have a high density of screws. The compatibility of various orthopedic implants with magnetic resonance imaging (MRI) has been studied [2-4], but the modern metallic pedicle-screw-rod systems have not been sufficiently investigated in this regard. A previously published study [1] on a pedicle-screw-rod system focused mainly on shorter implant constructs and used a field strength of $7 \mathrm{~T}$. However, the pedicle screw density used here was lower and the 7-T magnetic field strength was higher than in routine clinical care because usually the patients are examined at $1.5 \mathrm{~T}$ and $3 \mathrm{~T}$. Furthermore, not all aspects of MRI compatibility were examined; no attention was paid, for example, to magnetically induced torque or susceptibility artifacts. Patients with long metallic pedicle-screw-rod constructs who need a tomographic examination, e.g., in the presence of postoperative complications or in scoliosis secondary to tumors such as neurofibromas, often undergo computed tomography (CT) despite the exposure to ionizing radiation. Particularly due to the youth of many scoliosis patients, MRI would be preferable.

Before an examination with a given MRI scanner, it must be ensured that any metallic implants in the patient are MR conditional, i.e., pose no known hazards in a specified MRI environment with specified conditions of use. The American Society for Testing and Materials (ASTM) has defined standard methods for evaluation of passive implants to determine whether they are MR conditional and safe. During MRI, radiofrequencies (RF) are emitted with high energy, which can lead to induced heating of, and/or in the vicinity of, a passive medical implant (ASTM F2182 [5]). This heating can lead to injuries [6-8] and is one of the most common MRI incidents. Furthermore, the diagnostic value of MRI can be reduced by susceptibility artifacts $[9,10]$. These artifacts are characterized by distorted object geometry and artificial signal variations in the MR image caused by large susceptibility gradients between an implant and neighboring tissues (ASTM F2119 [11]). Additionally, even in the homogeneous area of the static magnetic field $\left(\mathrm{B}_{0}\right)$, strong magnetically induced torques may act on implanted ferromagnetic medical devices (ASTM F2213 [12]). These forces are liable to restrict the function of the device, damage it, and/or cause severe, sometimes life-threatening, incidents [13-15]. However, most serious injuries are caused by the magnetically induced displacement force $[8,16]$, because the spatial gradient of $\mathrm{B}_{0}$ can greatly accelerate ferromagnetic objects or metallic implants (ASTM F2052 [17]).

The objective of this study was to evaluate the MRI safety and MR conditional status of a metallic pedicle-screw-rod system of different lengths (130 to $430 \mathrm{~mm}$ ), configurations, and materials at field strengths of $1.5 \mathrm{~T}$ and $3 \mathrm{~T}$ adapted to a full-spine sawbone profile based on standardized testing methods of the ASTM.

\section{Materials and methods}

In the present study, a pedicle-screw-rod system (CD HORIZON® SOLERA ${ }^{\text {TM }}$ Spinal System, Medtronic) was mounted, the rods were bent to the anatomical shape, and screw length, position, and dimensions were adapted to the anatomical dimensions of a full-spine sawbone from thoracic vertebra 3 to lumbar vertebra 5 (14 segments, $430 \mathrm{~mm}$, Fig. 1a-d). This implant construct was systematically evaluated with standardized methods of the ASTM at field strengths of 1.5 T (Magnetom Avanto and Aera, Siemens) and $3 \mathrm{~T}$ (Magnetom Skyra and Prisma, Siemens). The rods were made of titanium (Ti) with different alloys (Table 1): pure titanium alloy (TiCP), titanium aluminide (TiAl), cobalt-chromium ( $\mathrm{CoCr}$ ), and cobalt-chromium-molybdenum (CoCr Plus). The screw heads consisted of $\mathrm{CoCr}$ and the threads of $\mathrm{Ti}$. The cross-links were also made from Ti.

The software SPSS Statistics version 25 (IBM) was used for statistical evaluation. A generalized linear model with post hoc Wald chi-squared tests was used to assess the influence of implant length, presence of cross-links, and magnetic field strength on RF-induced heating or susceptibility artifacts. The level of significance was set to $p<0.05$. The study has been approved by the local ethics committee of the Jena University Hospital (registration number 2020-1849-Daten) and performed in accordance with its relevant guidelines and regulations. Written informed consent was waived by the committee, as it was a retrospective analysis of standard-ofcare acquired image data.

\section{ASTM F2182: RF-induced heating}

The RF-induced heating was measured according to ASTM F2182 [5] with a TrueFISP sequence at $1.5 \mathrm{~T}$ (TR/TE 3.04/ $1.52 \mathrm{~ms}$, scan time $15 \mathrm{~min}$ ) and $3 \mathrm{~T}$ (TR/TE $500 / 48 \mathrm{~ms}$, scan time $15 \mathrm{~min}$ ) with a whole-body specific absorption rate (SAR) of $2 \mathrm{~W} / \mathrm{kg}$ for an assumed patient of weight $72.0 \mathrm{~kg}$, height $166 \mathrm{~cm}$, and age 40 years. The implant was hung from a wooden rod using thin plastic cords (Fig. 1e). This setup was immersed in a gel phantom (length $780 \mathrm{~mm}$, width $560 \mathrm{~mm}$, height $180 \mathrm{~mm}$ ) filled with distilled water, $1.32 \mathrm{~g} / \mathrm{l}$ sodium chloride $(\mathrm{NaCl})$, and $10 \mathrm{~g} / \mathrm{l}$ polyacrylic acid (PAA). The phantom was left in the scanner room for $24 \mathrm{~h}$ before measurements to adapt to the surrounding room temperature of around $23.5{ }^{\circ} \mathrm{C}$. The temperature was measured every $2 \mathrm{~s}$ at four points (Fig. 1f) with fiberoptic sensors (Reflex Signal Conditioner, Neoptix). Twelve configurations were analyzed: 
Table 1 Implant characteristics

\begin{tabular}{lllll}
\hline Type & Version & Manufacturer number & Length $\times$ diameter $(\mathrm{mm})$ & Material \\
\hline Rod & 1553200500 & $0224584 \mathrm{~W}$ & Variable $\times 5.50$ & TiCP \\
& 1554200500 & $0411249 \mathrm{~W}$ & Variable $\times 5.50$ & TiAl \\
& 1555006150 & $0465970 \mathrm{~W}$ & Variable $\times 5.50$ & CoCr \\
& 1556000500 & $0204211 \mathrm{~W}$ & Variable $\times 5.50$ & CoCr Plus \\
Screw & 55840005540 & H5344532 & $40.00 \times 5.50$ & Head CoCr, thread Ti \\
Cross-link & 8115528 & & $44.00 \times 17.00^{1}$ & Ti \\
\hline
\end{tabular}

${ }^{1}$ length $\times$ width $(\mathrm{mm})$

two CoCr rods (see version 1555006150 in Table 1) without and with two cross-links (see version 8115528 in Table 1) in lengths of $430 \mathrm{~mm}$ with 30 screws, $400 \mathrm{~mm}$ with 28 screws, $300 \mathrm{~mm}$ with 20 screws, $260 \mathrm{~mm}$ with 16 screws, $200 \mathrm{~mm}$ with 12 screws, and $130 \mathrm{~mm}$ with 8 screws. For the configurations without cross-links, a piece of wood was placed between the two rods to serve as a placeholder, preventing contact between the two rods. The measurements ( $n=3$ for each configuration) were performed with the implants placed parallel to $\mathrm{B}_{0}$. In total, 72 (twelve configurations $\times$ three measurements per configuration $\times$ two $\mathrm{B}_{0}$ ) measurements were performed.

\section{ASTM F2119: susceptibility artifact}

The susceptibility artifacts were measured according to ASTM F2119 [11] with a turbo spin echo sequence (TSE; TR $500 \mathrm{~ms}$, TE 24-25 ms, echo train length 7) and gradient echo sequence (GRE; TR $100 \mathrm{~ms}$, TE $15 \mathrm{~ms}$, flip angle $30^{\circ}$ ). The voxel size was adjusted to the implant container size used for measurement $(2 \times 2 \times 5 \mathrm{~mm}$ for large and $0.6 \times 0.6 \times 3 \mathrm{~mm}$ for small containers). The implant was hung from a wooden rod using thin plastic cords (Fig. 1e). This setup was immersed in a $1.5 \mathrm{~g} / 1$ copper sulfate solution $\left(\mathrm{CuSO}_{4}\right)$ in a large container (length $790 \mathrm{~mm}$, width $390 \mathrm{~mm}$, height $170 \mathrm{~mm}$ ) for long implants (> $80 \mathrm{~mm}$ length) and in a small container (length $230 \mathrm{~mm}$, width $160 \mathrm{~mm}$, height $150 \mathrm{~mm}$ ) for short implants ( $80 \mathrm{~mm}$ length). Including change of phase- and frequencyencoding direction, each measurement series consisted of 12 sequences (two pulse sequences, three slice directions, two frequency directions). The evaluation was performed with the tool MR-Susceptibility Artefact Measurement (SAM) [10] and histogram-based reference value. The artifact width is the maximum distance from the edge of the implant to the fringe of the resulting susceptibility artifact. In total, there were 18 configurations: without cross-links (one $\mathrm{CoCr}$ rod,

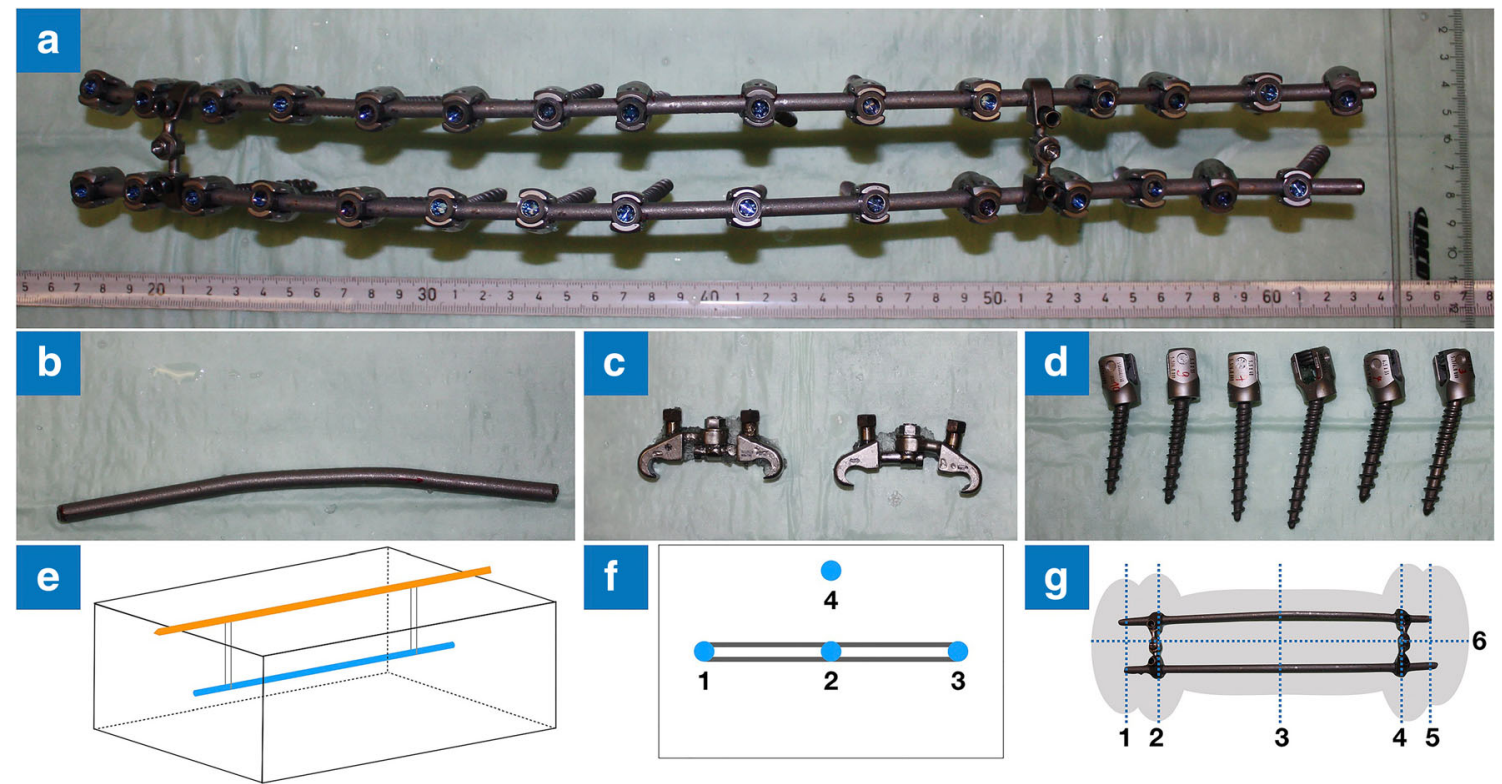

Fig. 1 The implant examined in this study with (a) a pedicle-screw-rod system consisting of (b) titanium with cobalt-chromium alloy rods, (c) titanium cross-links, and (d) titanium with cobalt-chromium alloy screws. For the measurements, (e) the implant was hung from a wooden rod using thin plastic cords. The RF-induced heating was measured (f) at four points (1-3: middle and ends of implant; 4: reference). The susceptibility artifact was measured (g) at six points (1,3, and 5: middle and ends of implant; 2 and 4: at position of cross-link; 6: along longitudinal axis of implant) 
see Table 1) and with two cross-links (two CoCr rods, see Table 1), each measured with lengths of $430 \mathrm{~mm}, 400 \mathrm{~mm}$, $350 \mathrm{~mm}, 300 \mathrm{~mm}, 260 \mathrm{~mm}, 250 \mathrm{~mm}, 200 \mathrm{~mm}, 150 \mathrm{~mm}$, and $130 \mathrm{~mm}$ without screws. The measurements were performed with the implants placed parallel to $\mathrm{B}_{0}$. Moreover, and according to the ASTM F2119, the susceptibility artifacts for all rods with a length of $80 \mathrm{~mm}$ (see Table 1) were evaluated without screws with the object placed parallel and perpendicular to $\mathrm{B}_{0}$ without and with metal artifact reduction technique "WARP" and a view-angle-tilting (VAT) of $30 \%$. The screw and crosslink were measured with the object placed perpendicular to $\mathrm{B}_{0}$. In total, $768 \mathrm{MRI}$ sequences were evaluated with approximately 3400 measurements.

\section{ASTM F2213 and F2052: magnetically induced torque and displacement force}

The magnetically induced torque was measured according to ASTM F2213 [12] with a digital apparatus [18]. For this, an MRI-safe measuring platform was combined with a precision balance (PCB 1600-2, Kern \& Sohn GmbH). The evaluation was performed for all rods with a length of $80 \mathrm{~mm}$, the screw, and cross-link (see Table 1). Additionally, a CoCr rod with a length of $130 \mathrm{~mm}$ was examined to derive the magnetically induced torque for larger rod lengths. The torque was measured at 10-degree increments as the test object was rotated relative to $\mathrm{B}_{0}$ for a horizontal orientation. In total, 504 measurements were performed.

The magnetically induced displacement force was measured according to ASTM F2052 [17] with an MRI-safe holding structure that contained a protractor with $1^{\circ}$ graduated markings. The deflection force was measured $(n=3)$ by the largest spatial gradient of $\mathrm{B}_{0}(11 \mathrm{~T} / \mathrm{m})$ at the entrance of the tube. The evaluation was performed for all rods with a length of $80 \mathrm{~mm}$, the screw, and the cross-link (see Table 1). Additionally, a CoCr rod with a length of $130 \mathrm{~mm}$ was examined. In total, 42 measurements were performed.

\section{Results}

The pedicle-screw-rod system could be reliably and safely examined in all combinations of length, configuration, and material in $\mathrm{a}_{0}$ at $1.5 \mathrm{~T}$ and $3 \mathrm{~T}$. There were no hazards or critical moments over the time.

\section{ASTM F2182: RF-induced heating}

The maximum RF-induced heating was $0.9 \mathrm{~K}$ at $1.5 \mathrm{~T}$ and $1.3 \mathrm{~K}$ at $3 \mathrm{~T}$ for all measurements (Fig. 2). On average, the RFinduced heating was $0.24 \pm 0.08 \mathrm{~K}$ (without cross-links) and $0.09 \pm 0.05 \mathrm{~K}$ (with cross-links) for $1.5 \mathrm{~T}$ and $0.50 \pm 0.16 \mathrm{~K}$ (without cross-links) and $0.35 \pm 0.14 \mathrm{~K}$ (with cross-links) for
3 T. RF-induced heating was significantly influenced by $\mathrm{B}_{0}(p$ $<0.001)$, implant length $(p=0.048)$, and presence of crosslinks $(p=0.001)$. In general, the RF-induced heating was significantly greater without cross-links $(1.5 \mathrm{~T}$ : $0.15 \mathrm{~K}, p<$ 0.001 with $95 \%$ CI $[0.08 ; 0.22] ; 3 \mathrm{~T}: 0.15 \mathrm{~K}, p<0.01$ with $95 \%$ CI $[0.04 ; 0.27])$. At a $\mathrm{B}_{0}$ of $1.5 \mathrm{~T}$, no significant relationship between RF-induced heating and implant length was found ( $p$ values between 0.089 and 0.884 ). On the other hand, comparing the implant heating between different implant lengths at a $\mathrm{B}_{0}$ of $3 \mathrm{~T}$, the RF-induced heating in implants of $200 \mathrm{~mm}$ was significantly greater than in longer (except 260 $\mathrm{mm}$ ) or shorter implants (see Table 2).

\section{ASTM F2119: susceptibility artifact}

The maximum artifact width (distance between implant surface and end of signal extinction) for different lengths of the anatomically bent $\mathrm{Ti}$ rods with $\mathrm{CoCr}$ alloy ranged between $14.77 \pm 2.93 \mathrm{~mm}$ (TSE) and $17.49 \pm 1.82 \mathrm{~mm}$ (GRE) for $1.5 \mathrm{~T}$ and between $23.67 \pm 2.39 \mathrm{~mm}(\mathrm{TSE})$ and $27.77 \pm$ $2.37 \mathrm{~mm}$ (GRE) for $3 \mathrm{~T}$ (Fig. 3). The largest artifact widths were measured at the edge of the implant. The maximum artifact widths were greater for GRE sequences than for TSE sequences $(1.5 \mathrm{~T}$ : $1.7 \mathrm{~mm}, p<0.001$ with $95 \% \mathrm{CI}[0.70$; 2.80]; 3 T: $4.4 \mathrm{~mm}, p<0.001$ with $95 \%$ CI [2.90; 5.80]).

For the straight rods with different alloys, TiCP and TiAl showed the smallest and $\mathrm{CoCr}$ and $\mathrm{CoCr}$ Plus the largest artifact widths (Fig. 4, Table 1). With the objects placed parallel (perpendicular) to $\mathrm{B}_{0}$, the maximum artifact widths of the rods for a TSE sequence were as follows: TiCP, $4.97 \pm 1.11 \mathrm{~mm}$ $(11.01 \pm 1.69 \mathrm{~mm})$; TiAl, $4.67 \pm 1.26 \mathrm{~mm}$ (9.58 $\pm 1.72 \mathrm{~mm})$; CoCr, $9.76 \pm 0.42 \mathrm{~mm}$ (19.42 $\pm 4.74 \mathrm{~mm})$; and CoCr Plus, $9.66 \pm$ $1.78 \mathrm{~mm}(19.01 \pm 3.71 \mathrm{~mm})$. For a GRE sequence, the maximum artifact widths were as follows: TiCP, $10.92 \pm 3.53 \mathrm{~mm}(20.04 \pm$ $2.49 \mathrm{~mm})$; TiAl, $9.39 \pm 1.66 \mathrm{~mm}(19.81 \pm 3.67 \mathrm{~mm})$; CoCr, 23.75

Table 2 The RF-induced heating of titanium rods with $\mathrm{CoCr}$ alloy in different length at $3 \mathrm{~T}$ (compare with Fig. 2 right) were compared by a generalized linear model with post hoc Wald chi-squared tests. The level of significance was set to $p<0.05$, and significant $p$ values are shown in italics. At a $\mathrm{B}_{0}$ of $1.5 \mathrm{~T}$, no significant relationship between RF-induced heating and implant length was found

\begin{tabular}{lrrrrrrr}
\hline Length (mm) & \multicolumn{7}{l}{$p$ value } \\
\cline { 2 - 7 } & 130 & 200 & 260 & 300 & \multicolumn{1}{l}{400} & \multicolumn{1}{l}{430} \\
\hline 130 & & 0.027 & 0.064 & 1.000 & 0.338 & 0.059 \\
200 & 0.027 & & 0.461 & 0.010 & $<0.001$ & $<0.001$ \\
260 & 0.064 & 0.461 & & 0.020 & $<0.001$ & $<0.001$ \\
300 & 1.000 & 0.010 & 0.020 & & 0.160 & 0.027 \\
400 & 0.338 & $<0.001$ & $<0.001$ & 0.160 & & 0.112 \\
430 & 0.059 & $<0.001$ & $<0.001$ & 0.027 & 0.112 & \\
\hline
\end{tabular}



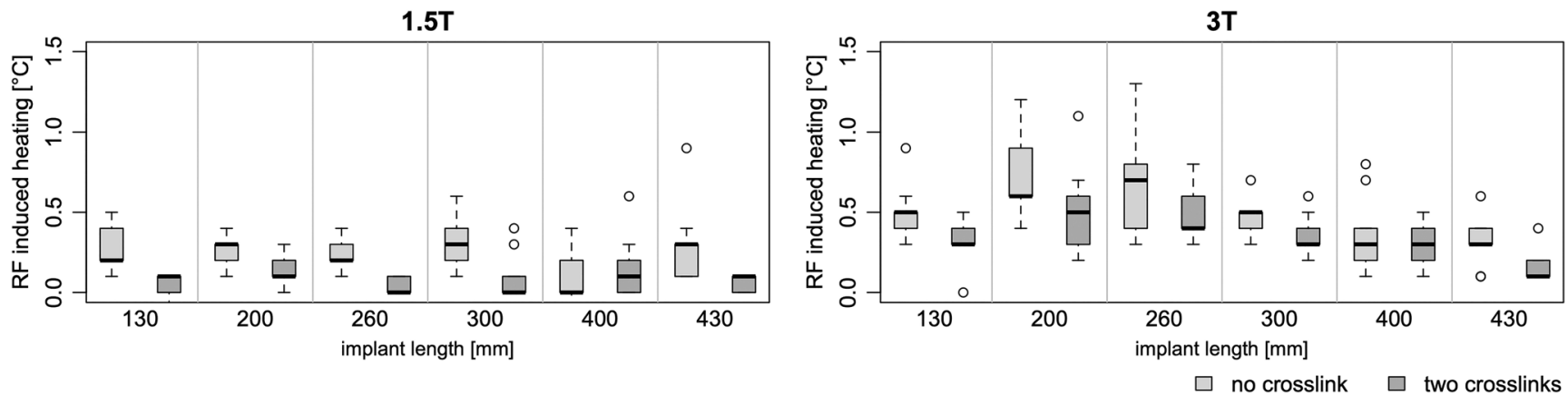

Fig. 2 The maximum RF-induced heating of the titanium rods with $\mathrm{CoCr}$ alloy with no and two cross-links at $1.5 \mathrm{~T}$ (left) and $3 \mathrm{~T}$ (right) for different implant lengths. A spine model was used to bend the rods and position the screws anatomically correctly

$\pm 1.51 \mathrm{~mm}(34.95 \pm 2.61 \mathrm{~mm}) ;$ and CoCr Plus, $19.22 \pm 3.19 \mathrm{~mm}$ $(35.56 \pm 6.27 \mathrm{~mm})$. No significant difference in maximum artifact size was found between the materials TiCP and TiAl or between $\mathrm{CoCr}$ and $\mathrm{CoCr}$ Plus. However, the artifact size for group 1 (TiCP, TiAl) is significantly lower $(9.84 \mathrm{~mm}, p<0.001$ with $95 \%$ CI [7.86; 11.81]) than for group 2 (CoCr, CoCr Plus).

Using the metal artifact reduction technique WARP with a VAT of $30 \%$, the artifact size was reduced by $14 \pm 6 \%$ (Fig. 4 , bottom left). The application enables significant reduction of artifact widths ( $1.34 \mathrm{~mm}, p<0.01$ with $95 \%$ CI $[0.34 ; 2.33])$.

For the cross-link and screw, the artifact widths at $1.5 \mathrm{~T}(3$ T) were $8.30 \pm 0.61 \mathrm{~mm}(13.19 \pm 2.54 \mathrm{~mm})$ for a TSE and $17.05 \pm 2.51 \mathrm{~mm}(19.85 \pm 5.15 \mathrm{~mm})$ for a GRE sequence (Fig. 4 , bottom right).

\section{ASTM F2213 and F2052: magnetically induced torque and displacement force}

For all investigated materials, the magnetically induced torque was less than $1 \mathrm{Nmm}$ at both $1.5 \mathrm{~T}$ and $3 \mathrm{~T}$. The maximum magnetically induced displacement angle at 1.5 $\mathrm{T}(3 \mathrm{~T})$ was: $\mathrm{TiCP}, 1.0^{\circ} \pm 0.5^{\circ}\left(2.0^{\circ} \pm 0.5^{\circ}\right)$; $\mathrm{TiAl}, 1.5^{\circ} \pm$ $0.5^{\circ}\left(2.0^{\circ} \pm 0.5^{\circ}\right) ; \mathrm{CoCr}, 2.0^{\circ} \pm 0.5^{\circ}\left(6.0^{\circ} \pm 0.5^{\circ}\right)$; and CoCr Plus, $2.0^{\circ} \pm 0.5^{\circ}\left(6.0^{\circ} \pm 0.5^{\circ}\right)$ for the rods with a length of $80 \mathrm{~mm}$. For the rod with $\mathrm{CoCr}$ alloy and a length of $130 \mathrm{~mm}$, the screw, and the cross-link, the maximum magnetically induced displacement angle at $1.5 \mathrm{~T}(3 \mathrm{~T})$ was $2.0^{\circ} \pm 0.5^{\circ}\left(7.0^{\circ} \pm 0.5^{\circ}\right), 2.0^{\circ} \pm 0.5^{\circ}\left(5.0^{\circ} \pm 0.5^{\circ}\right)$, and $1.0^{\circ} \pm 0.5^{\circ}\left(2.0^{\circ} \pm 0.5^{\circ}\right)$, respectively.
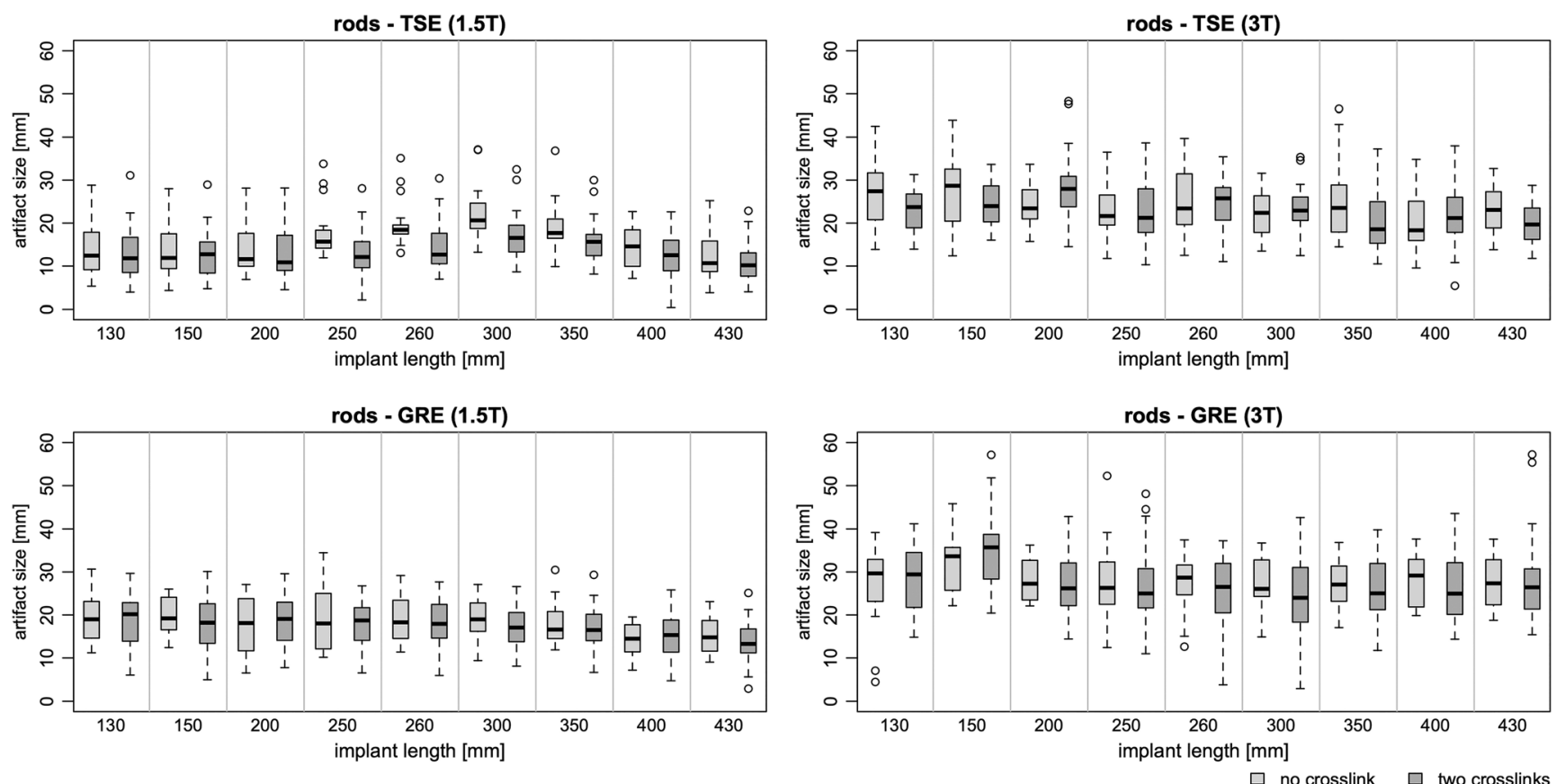

Fig. 3 The maximum artifact width for a TSE (above) and a GRE (below) sequence for the titanium rods with CoCr alloy without and with two crosslinks at $1.5 \mathrm{~T}$ (left) and $3 \mathrm{~T}$ (right) for different implant lengths. A spine model was used to bend the rods anatomically 

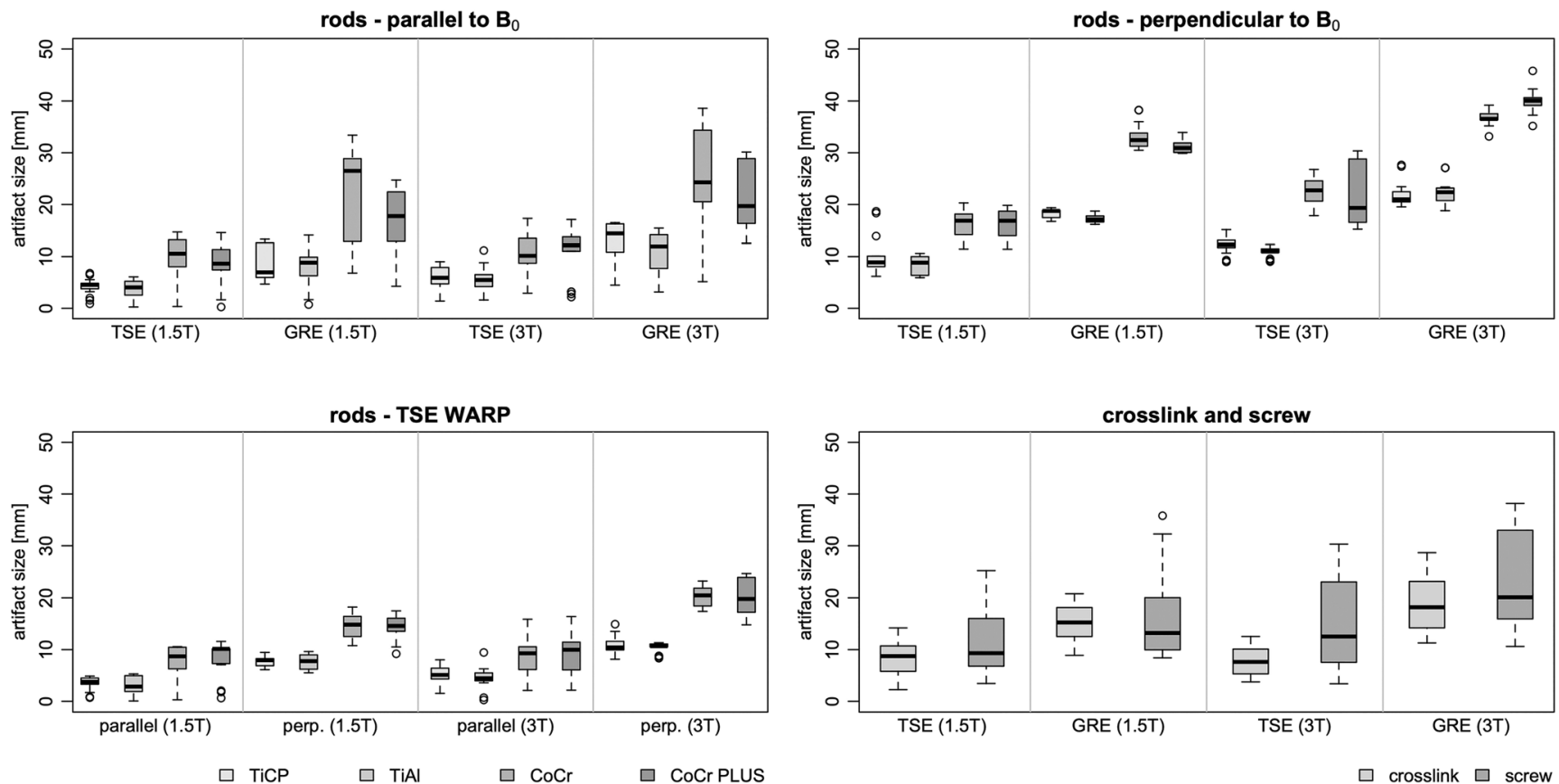

Fig. 4 The maximum artifact width for a parallel (top left) and perpendicular (top right) alignment of the longitudinal axis to $\mathrm{B}_{0}$ for four straight rods with different alloys (see Table 1). Additionally, the

metal artifact reduction technique WARP was evaluated (bottom left). At bottom right the maximum artifact width for the screw and cross-link (see Table 1) is shown

\section{Discussion}

The objective of this study was to evaluate the MRI safety and MR conditional status of a metallic pedicle-screw-rod system with different lengths (130 to $430 \mathrm{~mm}$ ), configurations, and materials at magnetic field strengths of $1.5 \mathrm{~T}$ and $3 \mathrm{~T}$ based on standardized test methods of the ASTM. We found that even long implant constructs are MR conditional and safe in the standard clinical setting for MRI in patients with such implants with regard to RF-induced heating as well as magnetically induced torque and displacement force. However, we encountered clinically relevant susceptibility artifacts near the posterior spinal implants which were dependent on the field strength.

\section{ASTM F2182: RF-induced heating}

In the present study, we examined metallic spinal implants ranging from 3 to 14 spinal segments $(130-430 \mathrm{~mm})$ in length, of the type usually employed for correction of scoliosis. Despite the considerable construct length and the large amount of metal, the maximum RF-induced temperature increase of the spinal implants in the worst case conditions (SAR $2 \mathrm{~W} / \mathrm{kg}, 15 \mathrm{~min}$ MR acquisition) was only $1.3 \mathrm{~K}$. The RF-induced heating was even less when two cross-links were used, although electrically closed loops (coils) can favor heating of the surroundings [19]. These results are in agreement with the findings of Tsukimura et al [1] for a 200-mm implant at $7 \mathrm{~T}$. A review [20] demonstrated that low heating

(up to $43{ }^{\circ} \mathrm{C}$ ) for several hours causes no damage and that heating to $44^{\circ} \mathrm{C}$ for 200 min leads only to transient erythema. Therefore, it can be assumed that adverse biological effects due to RF-induced heating of the investigated pedicle-screwrod system in scoliosis patients, examined with a 1.5 to $3 \mathrm{~T}$ MRI in a supine position, become unlikely. In vitro studies $[21,22]$ on RF-induced heating of metallic orthopedic implants showed temperature increases of up to 9 or $14 \mathrm{~K}$ after MRI duration of only $15 \mathrm{~min}$.

We found a critical length for effective heating [23-25] depending on the RF wavelength and implant length at $3 \mathrm{~T}$. Nevertheless, the amount of heating is very small. A possible reason for this is that the distance between implant and $\mathrm{RF}$ source has a large influence on RF-induced heating. In general, the RF-induced heating are strongest near the walls and weakest in the center of the MRI apparatus [26]. When the patient is lying supine, the implant is located in the middle of the scanner and therefore has the lowest risk of heating. Tsukimura et al [1] did not find any significant difference between Ti rods with different alloys. Moreover, the Ti rods with $\mathrm{CoCr}$ alloy have the ability to produce higher correction rates in adolescent idiopathic scoliosis (AIS) and provide significant and stable spinal correction compared to Ti rods with TiCP alloy of the same diameter [27]. For these reasons, this study carried out the complex measurement only for Ti rods with $\mathrm{CoCr}$ alloy in different configurations.

The automatic SAR limitation of the MR system [28] is country-specific designed for a maximum temperature (e.g., $24{ }^{\circ} \mathrm{C}$ ) and a maximum relative humidity (e.g., 60\%) in the 


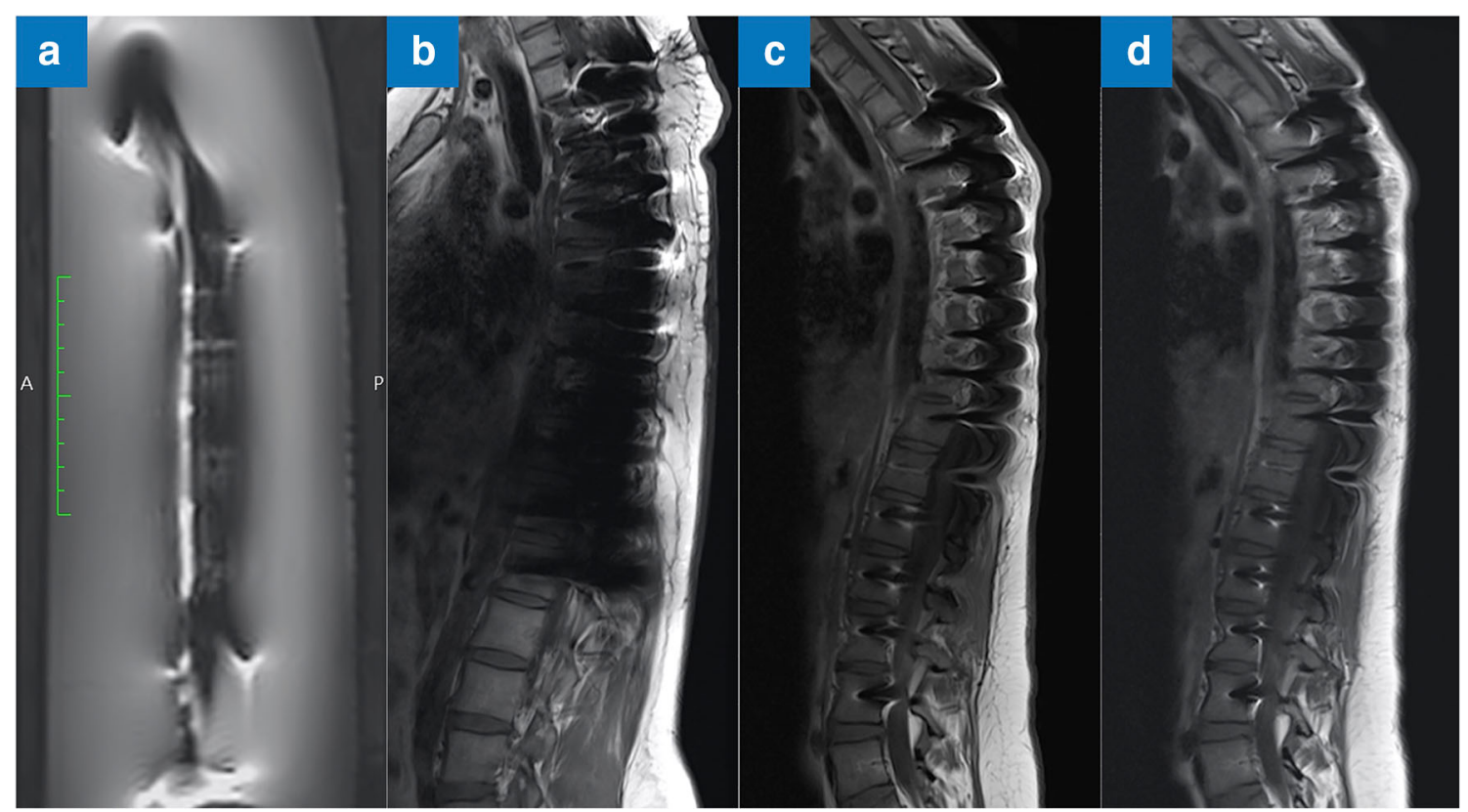

Fig. 5 MR images of a pedicle-screw-rod system approximately $300 \mathrm{~mm}$ long in a phantom (a, without screws) and in two volunteer patients at $3 \mathrm{~T}$ (b) and $1.5 \mathrm{~T}(\mathbf{c})$. Additionally, the effect of the artifact reduction method WARP is shown for $1.5 \mathrm{~T}(\mathbf{d})$

magnetic room. If the room temperature and/or the humidity is higher than specified above, compliance with the SAR limit values according to the International Electrotechnical Commission (IEC) or Federal Food and Drug Administration (FDA) guideline may no longer be ensured and therefore the SAR limits are reduced accordingly. This has the consequence that maybe some MR sequences are not available anymore. Only the sequence adaptation for SAR reduction remains possible. Besides this, the present and numerous other studies publications [1, 2, 7, 21-23, 26, 29, 30] were based on the original ASTM standard F2182 which suggests a whole-body SAR of approximately $2 \mathrm{~W} / \mathrm{kg}$.

\section{ASTM F2119: susceptibility artifact}

Susceptibility artifact can strongly reduce the diagnostic value of MRI, especially if the region of interest is close to the implant. This is the case, for example, for patients in whom postoperative hematoma or recurrent spinal tumor is suspected. Therefore, it is important to know which parameters influence the artifacts, in order to minimize it. In general, the size of susceptibility artifacts depends on the chemical elements present in the construct (implant material composition) [31], the geometry and volume of the implant [32], the magnetic field strength [33], the orientation of the implant in relation to $\mathrm{B}_{0}$ [31], the MRI sequence used [32], and the sequence parameters [31,33,34]. Comparison of the different rods in this study indicated that ferromagnetic cobalt is particularly likely to increase the susceptibility artifact. Avoiding the use of cobalt alloys might therefore reduce artifact size in cases where regular evaluation of the region adjacent to the implant is necessary.

Apart from the implant material, the size of susceptibility artifacts depends on the orientation of the implant in relation to $\mathrm{B}_{0}$, in agreement with previous studies $[9,31]$. The susceptibility artifacts will be lowest if the longest axes of the rod, screw, and cross-link are parallel to $\mathrm{B}_{0}$. Such alignment is not possible for an anatomically bent pedicle-screw-rod system. The bent section is no longer parallel to $\mathrm{B}_{0}$ and the angle can be of different sizes. Therefore, the rods were measured parallel (best case) and perpendicular (worst case) to $\mathrm{B}_{0}$ as recommended by the standard ASTM F2119 [11]. In spinal implants the screws and cross-links can almost always only be positioned perpendicular to $\mathrm{B}_{0}$, so for these components only this orientation was examined.

Magnetic field strength and sequence parameters also had a major effect on the susceptibility artifacts in the present study, indicating that lower (versus higher) field strength and TSE (versus GRE) sequences are beneficial with regard to artifact size. In Fig. 5, it is shown that especially at $3 \mathrm{~T}$ (Fig. 5a and b) the diagnostic value of MRI is strongly reduced in the region near the spinal implant. However, WARP can help reduce the artifacts caused by metal implants and therefore allows improved soft tissue evaluation [35, 36]. Nevertheless, for spinal implants, WARP does not automatically enable diagnostic evaluation of adjacent tissues (Fig. 5d). WARP can be used in three methods [28]: WARP with high bandwidth to reduce geometric distortions and changes in contrast, as well as, WARP with VAT technology to correct geometric in-plane distortions and WARP with VAT and slice encoding for metal artifact correction (SEMAC) to correct geometric through- 
plane distortions. The outcome of WARP with VAT depends largely on the type and orientation of the implant as well as other imaging parameters. Additionally, for warp with VAT and SEMAC, the number of SEMAC phase-encoding steps required depends on the size, shape, and material of the implant and can vary from patient to patient. Optimization of the WARP algorithm might lead to much better results than shown here but did not form part of the study. For departments where MRI is routinely performed in patients with scoliosis, we urgently suggest implementation of such routines.

\section{ASTM F2213 and F2052: magnetically induced torque and displacement force}

Under the conditions of the present study, the magnetically induced torque was negligible. In general, magnetically induced torque is minimal if the longitudinal axis of the test object is parallel to $\mathrm{B}_{0}$. This is almost exclusively the case for the rods (with the patient supine). Additionally, there is a linear relationship between the length of the test object and the magnetically induced torque [18]. However, even with vertical alignment of a rod $130 \mathrm{~mm}$ long, the magnetically induced torque was below $1 \mathrm{Nmm}$.

Regarding the magnetically induced displacement force, we found significantly greater angles for $3 \mathrm{~T}$ than for $1.5 \mathrm{~T}$. These results are basically in agreement with the findings of Tsukimura et al [1] at $3 \mathrm{~T}$. Nevertheless, since the angles for all test objects were far below $45^{\circ}$, they can be classified as safe according to the ASTM [17].

\section{Limitations}

The present study is not without limitations. First, all measurements were performed in a phantom. The real-life situation in patients can differ from idealized protocols. However, wellaccepted standard protocols were applied (ASTM). Second, all of the spinal implants tested were manufactured by the same company. Other companies may use different alloys for their implants, and this could influence the results, especially if the content of cobalt or other ferromagnetic metals is higher. Furthermore, we performed no optimization of the WARP sequences. Further studies are required to investigate the benefits of this technology for pedicle-screw-rod constructs.

\section{Conclusion}

In summary, large spinal implants are not necessarily a contraindication for MRI. Although susceptibility artifacts can severely limit the diagnostic capacity of MRI near the implants, the examination of other regions is safely possible. The RF-induced heating of the implant and the magnetically induced torque and displacement force are all at acceptable levels with the patient in the supine position. According to ASTM F2503 [37], the pedicle-screw-rod system is MR conditional in the following setting: patient in supine position, $\mathrm{B}_{0}$ of $1.5 \mathrm{~T}$ or $3 \mathrm{~T}$, and length of TiCP, TiAl, $\mathrm{CoCr}$, or $\mathrm{CoCr}$ Plus rods between 130 and $430 \mathrm{~mm}$.

Funding Open Access funding enabled and organized by Projekt DEAL.

\section{Compliance with ethical standards}

Guarantor The scientific guarantor of this publication is Andreas Heinrich.

Conflict of interest The authors of this manuscript declare no relationships with any companies whose products or services may be related to the subject matter of the article.

Statistics and biometry Two of the authors (Patrick Strube, Andreas Heinrich) have significant statistical expertise.

Informed consent Written informed consent was waived by the Institutional Review Board.

Ethical approval Institutional Review Board approval was obtained.

Methodology

- retrospective

- experimental

- performed at one institution

Open Access This article is licensed under a Creative Commons Attribution 4.0 International License, which permits use, sharing, adaptation, distribution and reproduction in any medium or format, as long as you give appropriate credit to the original author(s) and the source, provide a link to the Creative Commons licence, and indicate if changes were made. The images or other third party material in this article are included in the article's Creative Commons licence, unless indicated otherwise in a credit line to the material. If material is not included in the article's Creative Commons licence and your intended use is not permitted by statutory regulation or exceeds the permitted use, you will need to obtain permission directly from the copyright holder. To view a copy of this licence, visit http://creativecommons.org/licenses/by/4.0/.

\section{References}

1. Tsukimura I, Murakami H, Sasaki M et al (2017) Assessment of magnetic field interactions and radiofrequency-radiation-induced heating of metallic spinal implants in $7 \mathrm{~T}$ field. J Orthop Res 35: 1831-1837. https://doi.org/10.1002/jor.23464

2. Zou YF, Chu B, Wang CB, Hu ZY (2015) Evaluation of MR issues for the latest standard brands of orthopedic metal implants: plates and screws. Eur J Radiol 84:450-457. https://doi.org/10.1016/j. ejrad.2014.12.001 
3. McComb C, Allan D, Condon B (2009) Evaluation of the translational and rotational forces acting on a highly ferromagnetic orthopedic spinal implant in magnetic resonance imaging. J Magn Reson Imaging 29:449-453. https://doi.org/10.1002/jmri.21668

4. Rupp RE, Ebraheim NA, Wong FF (1996) The value of magnetic resonance imaging of the postoperative spine with titanium implants. J Spinal Disord 9:342-346

5. ASTM F2182-19E02 (2020) Standard test method for measurement of radio frequency induced heating on or near passive implants during magnetic resonance imaging. ASTM International, West Conshohocken. https://doi.org/10.1520/F2182-19E02

6. Zeng Q, Liu J, Angelone LM et al (2018) Investigation of RFinduced heating near interventional catheters at $1.5 \mathrm{~T}$ MRI: a combined modeling and experimental study. IEEE Trans Electromagn Compat 61:1423-1431. https://doi.org/10.1109/TEMC.2018. 2862249

7. Ono A, Arao S, Takata S, Gotanda T, Gotanda R, Tabuchi A (2019) Effect of weight input in magnetic resonance imaging system on radio-frequency-induced heating of metallic implants. World Congress on Medical Physics and Biomedical Engineering 2018. Springer, pp 11-14

8. Woods TO (2003) MRI Safety and Compatibility of Implants and Medical Devices. In: Winters GL, Nutt MJ, (eds). ASTM International, West Conshohocken, PA, pp 82-90. https://doi.org/ 10.1520/STP11156S

9. Heinrich A, Güttler FV, Schlesies F, Aschenbach R, Eckardt N, Teichgräber UK (2017) In vitro stent assessment by MRI: visibility of lumen and artifacts for 27 modern stents. Biomed Tech (Berl) 62: 565-573. https://doi.org/10.1515/bmt-2016-0008

10. Heinrich A, Teichgräber UK, Güttler FV (2015) Measurement of susceptibility artifacts with histogram-based reference value on magnetic resonance images according to standard ASTM F2119. Biomed Tech (Berl) 60:541-549. https://doi.org/10.1515/bmt2014-0184

11. ASTM F2119-07 (2013) Standard test method for evaluation of MR image artifacts from passive implants. ASTM International, West Conshohocken. https://doi.org/10.1520/F2119-07R13

12. ASTM F2213-17 (2017) Standard test method for measurement of magnetically induced torque on medical devices in the magnetic resonance environment. ASTM International, West Conshohocken. https://doi.org/10.1520/F2213-17.

13. Klucznik RP, Carrier DA, Pyka R, Haid RW (1993) Placement of a ferromagnetic intracerebral aneurysm clip in a magnetic field with a fatal outcome. Radiology 187:855-856. https://doi.org/10.1148/ radiology.187.3.8497645

14. Kelly W, Paglen P, Pearson J, Soloman M (1986) Ferromagnetism of intraocular foreign body causes unilateral blindness after MR study. AJNR Am J Neuroradiol 7:243-245

15. Jansson KF, Håkansson $\mathrm{B}$, Reinfeldt $\mathrm{S}$, Taghavi H, Eeg-Olofsson M (2014) MRI induced torque and demagnetization in retention magnets for a bone conduction implant. IEEE Trans Biomed Eng 61:1887-1893. https://doi.org/10.1109/TBME.2014.2309978

16. Güttler F, Heinrich A, Teichgräber U (2015) Whole-body ferromagnetic detector systems in clinical MRI. Radiologe 55:649653. https://doi.org/10.1007/s00117-015-2813-0

17. ASTM F2052-15 (2015) Standard test method for measurement of magnetically induced displacement force on medical devices in the magnetic resonance environment. ASTM International, West Conshohocken. https://doi.org/10.1520/F2052-15

18. Heinrich A, Dörschel J, Mashoor M, Güttler F, Teichgräber U (2019) Development of an Apparatus for Digital Measurement of Magnetically Induced Torque on Medical Implants to Facilitate the Application of the ASTM F2213 Standard. IEEE Trans Biomed Eng 66:3420-3425. https://doi.org/10.1109/TBME.2019.2905236
19. Muranaka H, Horiguchi T, Usui S et al (2006) Evaluation of RF heating on humerus implant in phantoms during 1.5 T MR imaging and comparisons with electromagnetic simulation. Magn Reson Med Sci 5:79-88. https://doi.org/10.2463/mrms.5.79

20. Goldstein LS, Dewhirst MW, Repacholi M, Kheifets L (2003) Summary, conclusions and recommendations: adverse temperature levels in the human body. Int J Hyperthermia 19:373-384. https:// doi.org/10.1080/0265673031000090701

21. Muranaka H, Horiguchi T, Ueda Y, Usui S, Tanki N, Nakamura O (2010) Evaluation of RF heating on hip joint implant in phantom during MRI examinations. Nihon Hoshasen Gijutsu Gakkai Zasshi 66:725-733. https://doi.org/10.6009/jjrt.66.725

22. Muranaka H, Horiguchi T, Ueda Y, Tanki N (2011) Evaluation of RF heating due to various implants during MR procedures. Magn Reson Med Sci 10:11-19. https://doi.org/10.2463/mrms.10.11

23. Langman DA, Goldberg IB, Finn JP, Ennis DB (2011) Pacemaker lead tip heating in abandoned and pacemaker-attached leads at 1.5 tesla MRI. J Magn Reson Imaging 33:426-431. https://doi.org/10. 1002/jmri.22463

24. Kainz W (2007) MR heating tests of MR critical implants. J Magn Reson Imaging 26:450-451. https://doi.org/10.1002/jmri.21020

25. Armenean C, Perrin E, Armenean M, Beuf O, Pilleul F, SaintJalmes H (2004) RF-induced temperature elevation along metallic wires in clinical magnetic resonance imaging: influence of diameter and length. Magn Reson Med 52:1200-1206. https://doi.org/10. 1002/mrm.20246

26. Nordbeck P, Fidler F, Weiss I et al (2008) Spatial distribution of RF-induced E-fields and implant heating in MRI. Magn Reson Med 60:312-319. https://doi.org/10.1002/mrm.21475

27. Etemadifar MR, Andalib A, Rahimian A, Nodushan SMHT (2018) Cobalt chromium-titanium rods versus titanium-titanium rods for treatment of adolescent idiopathic scoliosis; which type of rod has better postoperative outcomes? Rev Assoc Med Bras (1992) 64: 1085-1090. https://doi.org/10.1590/1806-9282.64.12.1085

28. Müller GM, Lundin B, von Schewelov T, Müller MF, Ekberg O, Månsson S (2015) Evaluation of metal artifacts in clinical MR images of patients with total hip arthroplasty using different metal artifact-reducing sequences. Skeletal Radiol 44:353-359. https:// doi.org/10.1007/s00256-014-2051-y

29. Liu Y, Chen J, Shellock FG, Kainz W (2013) Computational and experimental studies of an orthopedic implant: MRI-related heating at 1.5-T/64-MHz and 3-T/128-MHz. J Magn Reson Imaging 37: 491-497. https://doi.org/10.1002/jmri.23764

30. Yang R, Zheng J, Kainz W, Chen J (2017) Numerical investigations of MRI RF-induced heating for external fixation device in TEM and birdcage body coils at $3 \mathrm{~T}$. IEEE Trans Electromagn Compat 60:598-604. https://doi.org/10.1109/TEMC.2017. 2741420

31. Ganapathi M, Joseph G, Savage R, Jones A, Timms B, Lyons K (2002) MRI susceptibility artefacts related to scaphoid screws: the effect of screw type, screw orientation and imaging parameters. J Hand Surg Br 27:165-170. https://doi.org/10.1054/jhsb.2001.0717

32. Edwards MB, Taylor KM, Shellock FG (2000) Prosthetic heart valves: evaluation of magnetic field interactions, heating, and artifacts at 1.5 T. J Magn Reson Imaging 12:363-369. https://doi.org/ 10.1002/1522-2586(200008)12:2<363::aid-jmri21>3.0.co;2-3

33. Olsrud J, Lätt J, Brockstedt S, Romner B, Björkman-Burtscher IM (2005) Magnetic resonance imaging artifacts caused by aneurysm clips and shunt valves: dependence on field strength (1.5 and $3 \mathrm{~T})$ and imaging parameters. J Magn Reson Imaging 22:433-437. https://doi.org/10.1002/jmri.20391

34. Kolind SH, MacKay AL, Munk PL, Xiang QS (2004) Quantitative evaluation of metal artifact reduction techniques. J Magn Reson Imaging 20:487-495. https://doi.org/10.1002/jmri.20144 
35. Griffin JF IV, Archambault NS, Mankin JM et al (2013) Magnetic resonance imaging in cadaver dogs with metallic vertebral implants at 3 Tesla: evaluation of the WARP-turbo spin echo sequence. Spine (Phila Pa 1976) 38:E1548-1553. https://doi.org/10.1097/ BRS.0b013e3182a58b14

36. Gao F, Wei Y, Wei S, Kan X, Yinghui G (2017) Feasibility of reducing artifacts of spine metal implants at 3.0 T MRI. Chin J Radiol 51:519-524
37. ASTM F2503-20 (2020) Standard practice for marking medical devices and other items for safety in the magnetic resonance environment. ASTM International, West Conshohocken. https://doi. org/10.1520/F2503-20

Publisher's note Springer Nature remains neutral with regard to jurisdictional claims in published maps and institutional affiliations. 